\title{
No excess 12-year mortality in men with impaired glucose tolerance who participated in the Malmö Preventive Trial with diet and exercise
}

\author{
K.-F. Eriksson, F. Lindgärde \\ Department of Medicine, University Hospital, Malmö, Sweden
}

\begin{abstract}
Summary Impaired glucose tolerance (IGT) is associated with increased mortality due to ischaemic heart disease (IHD), but as it is not known whether this excess mortality can be reduced by preventing or delaying the development of non-insulin-dependent diabetes mellitus (NIDDM), a long-term NIDDM prevention trial of dietary counselling and physical exercise was launched at Malmö, Sweden, the 12-year follow-up of which is reported here. At 12-year follow-up of 6956 men who underwent health screening at 48 years of age, an IGT intervention group $(n=288)$ who participated in a long-term NIDDM prevention programme were compared with an IGT non-randomised routine treatment group ( $n=135)$, a diabetic group $(n=144)$, and the remainder, the normal glucose tolerance (NGT) group $(n=6389)$. The variables studied included the levels of blood glucose, plasma insulin, blood pressure, blood lipids, lung function and maximum oxygen uptake. Subjects with IGT were characterised by overweight, poor vital capacity, hypertension, hypertriglyceridaemia and hyperinsulinaemia. The mortal-
\end{abstract}

ity rate in the IGT intervention group was similar to that in the NGT group (6.5 vs 6.2 per 1000 person years at risk) and lower than that in the IGT routine treatment group (6.5 vs $14.0, p=0.009)$. In the two IGT groups taken together, intervention but not body mass index, systolic blood pressure, smoking, cholesterol or the 2-h glucose level predicted mortality. Systolic blood pressure was a predictor of IHD mortality among IGT subjects; and in the cohort as a whole, body mass index, systolic blood pressure, hypercholesterolaemica, diabetes and smoking were predictors of IHD mortality. The findings suggest that a long-term intervention programme, with an emphasis on lifestyle changes, including dietary counselling and physical exercise, will reduce mortality in subjects with IGT who are at an increased risk of both developing NIDDM and of premature death due to IHD and other causes. [Diabetologia (1998) 41: 1010-1016]

Keywords Impaired glucose tolerance, prevention, diet, exercise, mortality, risk factors.
Several studies in middle-aged men have consistently shown impaired glucose tolerance (IGT) to be associated with excess mortality, especially that due to

Received: 20 June 1997 and in revised form: 24 April 1998

Corresponding author: Dr. K.-F.Eriksson, Department of Medicine, Lund University, University Hospital, Malmö, S-20502 Malmö, Sweden

Abbreviations: NGT, Normal glucose tolerance; IGT, impaired glucose tolerance; IHD, ischaemic heart disease; NIDDM, non-insulin-dependent diabetes; GTT, glucose tolerance test; $\mathrm{BP}$, blood pressure. ischaemic heart disease (IHD) [1,2], whereas this association is not obvious in elderly people [3]. Controversy remains as to whether the macrovascular disease is attributable to the hyperglycaemia per se as is the case in microvascular disease, or to traditional risk factors (high blood pressure, hypercholesterolaemia, smoking etc.) [1]. Patients with IGT, a target group for non-insulin-dependent diabetes mellitus (NIDDM) prevention [4], are characterised by a sedentary way of life and poor physical fitness [5-7], coupled with insulin resistance [8]. In the general population both obesity and physical inactivity are associated with increased incidences of NIDDM [7, 9] and 
IHD [10]. A higher degree of leisure-time physical activity is associated with a reduced mortality from any cause and from IHD in both men and women [11-14]. Men beginning moderately vigorous sports activity have lower death rates than men who do not take up sports activity [15]. Strategies for the primary prevention of NIDDM should not only aim at the prevention of hyperglycaemia, but at the reduction of excess mortality [16]. However, NIDDM prevention studies showing any effect on such endpoints as IHD, myocardial infarction, stroke or death, are almost lacking. Indications of a beneficial effect on 6year mortality in the IGT diet and exercise subgroup were found by us in the Malmö prevention study [17] and in the subgroup treated with tolbutamide in the Malmöhus county study [2].

In the Malmö prevention study, 6956 48-year-old men underwent a health screening programme during the period 1975-79 [6], 423 men with IGT being identified as candidates to test the feasibility of an NIDDM prevention programme including diet and exercise. Because of department routine the study was not randomised except for the first 6-12 months. The study population as a whole (6956), i.e. including those with diabetes at the outset, have since been followed with regard to the development of diabetes (until the age of 54), and mortality and causes of death until their 60th birthday.

In the present study, which constitutes the latest phase of the prevention study, the overall aims were threefold; 1 . to ascertain whether, at the age of 60 , the IGT intervention group (i.e. men with IGT who participated in the NIDDM prevention programme) were still characterised by a survival rate comparable to that in the (normal glucose tolerance) NGT group, as was the case at the age of $54 ; 2$. to determine whether mortality in the IGT intervention group was lower than in the IGT routine treatment group (i.e. non-randomised non-participants in the NIDDM prevention programme); and 3. to identify possible predictors of death in the IGT subgroups and in the cohort as a whole.

\section{Subjects and methods}

Subjects. The original study population consisted of six birthyear cohorts comprising a total of 695648 -year-old men (born 1926-31) who underwent health screening including a duplicate glucose tolerance testing (GTT) in 1975-79 [6]. Conventional medical examination and treatment were offered to all patients with unregulated diabetes or hypertension (newly detected or previously known cases), hepatopathy (i.e. increased liver enzymes), hyperlipidaemia or minor disorders, subgroups accounting for approximately $25 \%$ of the cohort. Overweight men (> $125 \%$ of ideal weight) were given written dietary advice. Subjects with IGT were offered referral to a specially formed clinic for long-term intervention with diet and exercise [17].

The present study population thus consisted of four subgroups originally identified at a mean age of 48 years. The first of these was the diabetes subgroup of 144 patients with diabetes at the start of the study, of whom 101 were already known cases (34 of them being treated with insulin, and 67 with blood glucose lowering agents and/or diet), and 43 were newly detected at screening; those with newly detected diabetes and those with poor metabolic control were referred to the diabetes clinic. Of 423 men with IGT identified at two consecutive GTTs within a 2-3 week period, using local criteria [6] (the screening having been performed before the advent of the World Health Organization (WHO) criteria), 288 (the IGT intervention group) were assigned to the diet and exercise programme, and 135 (the IGT routine treatment group) were given basic advice etc., but were not assigned to the programme for various reasons (due to other check-ups; change of residency, could not or would not participate). There were no differences in the baseline glucose levels on either of the two GTTs [17]. The remainder of the cohort $(n=6389)$, referred to as the NGT group, were characterised either by normal glucose tolerance $(n=5577)$ or a non-reproducible, probably erroneous, abnormal GGT result $(n=812)$.

Measurements. Screening investigations were performed by specially trained nurses in the morning after the subjects had fasted overnight. The investigation included measurement of body height (nearest $\mathrm{cm}$ ), body weight, triceps skin fold (Harpenden callipers), forced lung capacity (Spirotron equipment), blood pressure and heart rate after $10 \mathrm{~min}$ rest, and an ECG. In a random sample $(n=641)$, maximum oxygen uptake $\left(\mathrm{VO}_{2}\right.$ max) was estimated during a bicycle ergometer test [5]. A computerised questionnaire was answered during glucose tolerance testing. A 2-h oral GTT was performed in $93 \%$ of the subjects, and a 90-min intravenous test (IVGTT) in 7\%. During the screening period 1974-79 the cut-off level for fasting and 2-h glucose at oral GTT was $120 \mathrm{mg} / \mathrm{dl}$, corresponding to approximately $7.0 \mathrm{mmol} / \mathrm{l}$ according to the SI system adopted in 1976. A glucose disappearance rate $\left(K_{t}\right)$ at IVGTT below $1.00 \% / \mathrm{min}$ was regarded as abnormal [6]. Capillary blood glucose was analysed with a hexokinase method, plasma insulin with a standard radioimmunoassay and blood lipids were analysed with standard methods.

Intervention and follow-up. The Malmö NIDDM prevention programme has been described in detail previously [17]. In brief the programme targeted the IGT group of the cohort, and the men were invited to participate in a long-term feasibility study with organised dietary therapy and physical exercise with annual check-ups over a 6-year period. Multiple physical and metabolic improvements (e.g. fitness, blood pressure, lipids, glucose and insulin levels) were achieved without more medication. At a mean age of 54, all men who were still resident in the Malmö region were invited to a second screening investigation in 1982-85 [7], after which the IGT intervention group was followed continuously on a regular clinical basis for another 6-year period. Those men in the IGT routine treatment group who had developed diabetes were referred to the diabetes clinic and those who still had IGT were again informed about the condition and given basic advice on lifestyle and diet. No further approach was made to the remainder of the cohort. Between the ages of 48 and 54, the average annual conversion rates to diabetes were $0.3,1.7$ and $4.6 \%$ for the NGT, IGT intervention and IGT routine treatment groups respectively [7]. No systematic prevalence data for the cohort are available at the age of 60 years.

Mortality. Mortality was monitored by scrutiny of the registry at Statistics Sweden (the national bureau of statistics), starting when the average age of the cohort was 48 years and continu- 
ing until their 60th birthday, a mean duration of follow-up of 12 years. Causes of death, obtained from death certification which in most cases was based on post-mortem reports (in Malmö at the time of the study, the autopsy rate was approximately $80 \%$ [18]), were classified according to ICD-9 codes: 410-414, ischaemic heart disease (IHD); 420-429, other heart disease; 430-438; cerebrovascular disease; and 140-239, malignancies; or designated 'other causes'.

Statistical analysis. Values are means \pm SEM. The $t$-test or the Wilcoxon test (triglycerides and insulin) were used to determine group differences and the Chisquare test to determine differences in frequencies. The Kaplan-Meyer life-table method was used for survival analyses, and the log-rank test for group comparisons. Mortality rates were calculated with exact $95 \%$ confidence intervals (C. I.). Regression analysis (Cox's proportional hazards model) was used to identify predictors of death. Values with skewed distributions were log transformed before testing.

\section{Results}

Overall (all-cause) mortality. Survival analysis showed the four study groups to differ markedly in mortality (Fig.1). Both the diabetes group and the IGT routine treatment group were characterised by early excess overall mortality, the respective death rates being 3 times $(p=0.0001)$ and 2 times $(p=$ $0.0003)$ greater than that of the NGT group. However, mortality in the IGT intervention group closely paralleled that of the NGT group, and by the age of 60 there was no difference in overall mortality between these two groups. Moreover, overall mortality in the IGT intervention group was significantly lower than that in the IGT routine treatment group ( $p=$ 0.009). Taking the two IGT groups together mortality was higher than in the NGT group (8.8 vs 6.2 per 1000 person years at risk, $p<0.05)$.

Causes of death. Specific causes of death are given in Table 1. Vascular deaths and deaths due to malignancies were of comparable frequency in the NGT group. In the IGT routine treatment group and the diabetes group, ischaemic heart disease was the ma-

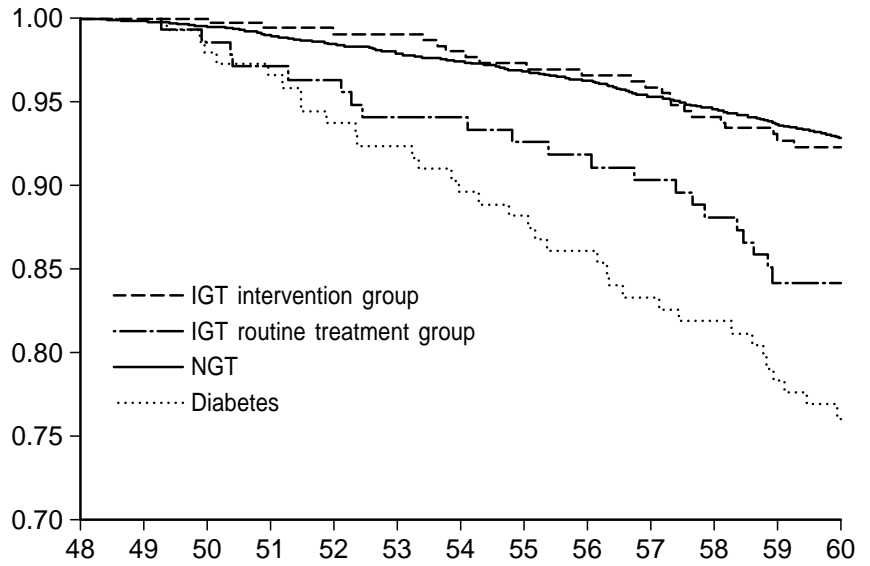

Fig. 1. Survival curves (Kaplan-Meyer life-table analysis) of the four study groups. Mortality in the IGT intervention group did not differ from that in the NGT group $(p=0.80)$, but was lower than that in the IGT routine treatment group $(p=$ $0.009)$ and that in the diabetes group $(p=0.0001)$ (log-rank test). $x$-axis: Age (years); $y$-axis: Proportion who survived

jor single cause of death, the frequency being 4-7 times greater than that in the NGT group $(p<$ $0.001)$. However, mortality due to IHD in the IGT intervention group was lower than that in the IGT routine treatment group or the diabetes group with risk ratios of 0.49 (95\% C.I. $0.20-1.25)$ and 0.24 (95\% C. I. 0.11-0.51) respectively, and only 2-times greater than that in the NGT group (risk ratio of 1.94 with 95\% C.I. 0.98-3.50). On the other hand, mortality due to non-vascular disease in the IGT intervention group was only half that in the NGT group, and only a third of that in the IGT routine treatment group $(p<0.05$ in both cases).

Baseline risk factors for NIDDM and cardiovascular disease. The frequency of a family history of diabetes increased with increasing impairment of glucose tolerance (Table 2). As compared with the NGT group, the diabetes group and both the IGT subgroups were characterised by greater weight gain in early middle age, less physical activity, and a somewhat lower pro-

Table 1. Mortality rates and causes of death (ICD 9) in the four study groups

\begin{tabular}{lllll}
\hline Study group & NGT & IGT intervention & IGT routine treatment & Diabetes \\
No. of men & 6389 & 288 & 135 & 144 \\
Person years at risk & 73805 & 3375 & 1503 & 1507 \\
No. of deaths & 456 & 22 & $7.3(3.7-13.1)^{\mathrm{a}}$ & 34 \\
\hline Ischaemic heart disease (410-414) & $1.8(1.5-2.2)$ & $3.6(1.8-6.2)$ & $0(-2.5)$ & $14.6(9.2-22.1)^{\mathrm{a}}$ \\
Other heart disease (420-429) & $0.3(0.2-0.4)$ & $0.3(0.01-1.7)$ & $1.3(0.2-4.8)$ & $0.7(0.02-3.7)$ \\
Cerebrovascular disease (430-438) & $0.1(0.06-0.2)$ & $0.9(0.2-2.6)$ & $2.0(0.4-5.8)$ & $0(-2.5)$ \\
Malignancies (140-239) & $2.0(1.7-2.4)$ & $1.5(0.5-3.5)$ & $3.3(1.1-7.8)$ & $0.7(0.02-3.7)$ \\
All other causes & $1.9(1.6-2.3)$ & $0.3(0.01-1.7)^{\mathrm{a}}$ & $14.0(8.7-21.4)^{\mathrm{a}}$ & $22.6(15.6-31.5)^{\mathrm{a}}$ \\
Total mortality & $6.2(5.7-6.8)$ & $6.5(4.1-9.9)^{\mathrm{b}}$ & $12.2)^{\mathrm{a}}$ & $2.6(15.6)$ \\
\hline
\end{tabular}

Figures are the mortality rates per 1000 person years at risk (95\% C. I.) by causes of death during the 12 -year study period. ${ }^{\mathrm{a}} p<0.05$ vs NGT group. ${ }^{\mathrm{b}} p<0.05$ vs IGT routine group, re- lative risk 0.47 (0.24-0.88). All other comparisons vs the NGT group and between the two IGT groups were not significant $(p \geq 0.05)$ 
Table 2. Frequencies (\%) of familiy history of diabetes, previous IHD and present sedentary lifestyle at the age of 48 years

\begin{tabular}{|c|c|c|c|c|}
\hline No. of men & NGT & $\begin{array}{l}\text { IGT inter- } \\
\text { vention } \\
288\end{array}$ & $\begin{array}{l}\text { IGT } \\
\text { routine } \\
\text { treatment } \\
135\end{array}$ & $\begin{array}{l}\text { Dia- } \\
\text { betes } \\
144\end{array}$ \\
\hline $\begin{array}{l}\text { Family history } \\
\text { of diabetes }\end{array}$ & 13 & $19^{\mathrm{b}}$ & $19^{\mathrm{a}}$ & $28^{\mathrm{c}}$ \\
\hline $\begin{array}{l}\text { Previous diagnosis } \\
\text { of IHD }\end{array}$ & 2.3 & 2.1 & 3.7 & $6.3^{\mathrm{b}}$ \\
\hline $\begin{array}{l}\text { Treatment for } \\
\text { hypertension }\end{array}$ & 4 & $14^{\mathrm{c}}$ & $16^{\mathrm{c}}$ & $14^{\mathrm{c}}$ \\
\hline Current smokers & 53 & $44^{\mathrm{b}}$ & $41^{\mathrm{a}}$ & 46 \\
\hline $\begin{array}{l}\text { Weight gain more } \\
\text { than } 10 \mathrm{~kg} \text { since } \\
\text { the age of } 30\end{array}$ & 28 & $49^{c}$ & $46^{\mathrm{c}}$ & $40^{\mathrm{b}}$ \\
\hline $\begin{array}{l}\text { Daily walking or } \\
\text { bicycling to work }\end{array}$ & 30 & $23^{\mathrm{a}}$ & $22^{\mathrm{d}}$ & 24 \\
\hline
\end{tabular}

${ }^{\mathrm{a}-\mathrm{c}} p<0.05-0.001$ vs NGT group. ${ }^{\mathrm{d}} 0.05<p<0.10$ vs NGT group. No significant differences were found between the two IGT groups

portion of smokers. Hypertension was significantly more prevalent among all of the glucose intolerant groups, the frequency being comparable in the IGT groups and the diabetes group. The frequency of a previous diagnosis of IHD (angina or myocardial infarction) was low, being increased in the diabetic group only.

As clearly shown in Table 3, men of this age group with IGT and diabetes are more obese (e.g. increased BMI and subcutaneous fat layer) and less fit (e.g. higher resting heart rate and lower vital capacity) than men with normal glucose tolerance. They are also characterised by high blood pressure, hyperlipidaemia, higher fasting glucose level and hyperinsulinaemia. A higher proportion of the IGT groups than expected were found to have values within the 5 th quintile for fasting insulin, blood pressure, trigly- cerides, the most extreme value being the 2-h insulin level for which 3 or 4 subjects had values in the 5 th quintile (data not shown). Except for a small difference in blood pressure, the two IGT subgroups had a comparable physical and metabolic profile.

Predictors of death in IGT subjects (Table 4). For the purpose of identifying possible predictors of death, the two IGT subgroups were combined. A minor set of variables was selected with regard to the number of events and to avoid highly correlated variables. For 392 of the 423 subjects, complete data were available for body mass index (BMI), smoking, systolic BP (blood pressure), cholesterol, 2-h glucose, previous myocardial infarction or angina (IHD), and intervention. $385(91 \%)$ free of IHD were included in a Cox regression model. In a stepwise procedure all-cause mortality (10\% [38/385]) was predicted by intervention only with a risk ratio of $0.45(95 \%$ C.I. $0.24-0.85, p=0.012$ ), followed by systolic BP, and smoking $(0.10<p<0.20$ for both) when all variables were kept in the model (forward selection procedure) (Table 4). IHD mortality (5\% [20/385]) was predicted by systolic BP only in the stepwise procedure ( $p=$ $0.016)$, followed in a forward selection procedure by BMI $(p=0.069)$ and smoking $(p=0.19)$. The same result was obtained also after the exclusion of subjects who died from other causes $(n=18)$. Both for all-cause and IHD mortality, all other variables had $p$-values greater than 0.20 .

Risk factors for death in the cohort as a whole (Table 5). Values for relevant variables from Tables 2 and 3 were subjected to regression analysis (Cox's proportional hazards model) to identify possible risk factors for all-cause mortality and for IHD mortality. Only men free of IHD at entry were included. Complete data for BMI, smoking, systolic BP, cholesterol, forcecd vital capacity, fasting blood glucose, presence

Table 3. Baseline characteristics by groups

\begin{tabular}{|c|c|c|c|c|}
\hline No. of men & $\begin{array}{l}\text { NGT } \\
6389\end{array}$ & $\begin{array}{l}\text { IGT intervention } \\
288\end{array}$ & $\begin{array}{l}\text { IGT routine treatment } \\
135\end{array}$ & $\begin{array}{l}\text { Diabetes } \\
144\end{array}$ \\
\hline Body mass index $\left(\mathrm{kg} / \mathrm{m}^{2}\right)$ & $24.8 \pm 0.1$ & $27.1 \pm 0.2^{c}$ & $26.8 \pm 0.4^{\mathrm{c}}$ & $26.9 \pm 0.4^{\mathrm{c}}$ \\
\hline Height $(\mathrm{cm})$ & $176.3 \pm 0.1$ & $175.5 \pm 0.4^{\mathrm{a}}$ & $176.6 \pm 0.6$ & $174.4 \pm 0.6^{b}$ \\
\hline Weight $(\mathrm{kg})$ & $77.1 \pm 0.1$ & $83.4 \pm 0.7^{\mathrm{c}}$ & $83.5 \pm 1.2^{\mathrm{c}}$ & $82.1 \pm 1.3^{\mathrm{c}}$ \\
\hline Triceps skin fold index (mm) & $10.6 \pm 0.1$ & $12.2 \pm 0.2^{\mathrm{c}}$ & $12.7 \pm 0.1^{\mathrm{c}}$ & $11.5 \pm 0.2^{\mathrm{c}}$ \\
\hline Resting heart rate (beats/min) & $68.3 \pm 0.1$ & $70.9 \pm 0.7^{\mathrm{c}}$ & $72.6 \pm 1.0^{\mathrm{c}}$ & $73.8 \pm 1.0^{\mathrm{c}}$ \\
\hline Forced vital capacity (1) & $4.33 \pm 0.02$ & $4.18 \pm 0.05^{\mathrm{a}}$ & $4.06 \pm 0.08^{\mathrm{b}}$ & $3.94 \pm 0.09^{c}$ \\
\hline Systolic BP $(\mathrm{mm} \mathrm{Hg})$ & $129.9 \pm 0.2$ & $138.0 \pm 1.0^{\mathrm{c}, \mathrm{f}}$ & $144.4 \pm 1.9^{\mathrm{c}}$ & $139.9 \pm 1.7^{\mathrm{c}}$ \\
\hline Diastolic BP (mm Hg) & $87.6 \pm 0.1$ & $92.2 \pm 0.6^{\mathrm{c}, \mathrm{f}}$ & $96.6 \pm 1.1^{\mathrm{c}}$ & $91.2 \pm 1.1^{\mathrm{c}}$ \\
\hline Cholesterol $(\mathrm{mmol} / \mathrm{l})$ & $5.79 \pm 0.01$ & $5.95 \pm 0.06^{\mathrm{b}}$ & $6.07 \pm 0.10^{c}$ & $5.89 \pm 0.14$ \\
\hline Triglycerides $(\mathrm{mmol} / \mathrm{l})$ & $1.56 \pm 0.01$ & $2.25 \pm 0.12^{\mathrm{c}}$ & $2.13 \pm 0.11^{\mathrm{c}}$ & $2.59 \pm 0.17^{\mathrm{c}}$ \\
\hline Fasting blood glucose $(\mathrm{mmol} / \mathrm{l})$ & $4.7 \pm 0.1$ & $5.3 \pm 0.1^{\mathrm{c}}$ & $5.3 \pm 0.1^{\mathrm{c}}$ & $9.7 \pm 0.3^{c}$ \\
\hline 2-h blood glucose at OGTT (mmol/l) & $5.3 \pm 0.1$ & $8.4 \pm 0.1^{\mathrm{c}}$ & $8.6 \pm 0.1^{\mathrm{c}}$ & $12.5 \pm 0.6^{\mathrm{c}}$ \\
\hline Fasting insulin $(\mathrm{pmol} / \mathrm{l})$ & $75.3 \pm 1.0$ & $120.5 \pm 7.3^{c}$ & $131.3 \pm 11.3^{\mathrm{c}}$ & $170.8 \pm 24.4^{\mathrm{c}}$ \\
\hline 2-h insulin at OGTT $(\mathrm{pmol} / \mathrm{l})$ & $241.8 \pm 3.6$ & $699.3 \pm 37.3^{\mathrm{c}}$ & $685.9 \pm 46.6^{c}$ & $542.4 \pm 66.0^{c}$ \\
\hline
\end{tabular}

Values are means \pm SE. In the diabetes group OGTT was performed in previously undiagnosed cases only. ${ }^{\mathrm{a}-\mathrm{c}} p<0.05-0.001$ compared with the NGT group; ${ }^{\mathrm{d}-\mathrm{f}} p<0.05-0.001$ between the two IGT groups, whereas all other values were not significantly different 
Table 4. Independent risk factors for death from any cause in the IGT groups

\begin{tabular}{llll}
\hline & $\begin{array}{l}\text { Risk } \\
\text { ratio }\end{array}$ & $\begin{array}{l}\text { 95\% confi- } \\
\text { dence interval }\end{array}$ & $p$-value \\
\hline Body mass index & 1.01 & $0.92-1.09$ & 0.78 \\
Current smoking (Yes vs No) & 1.64 & $0.82-2.89$ & 0.14 \\
Systolic BP & 1.01 & $0.99-1.03$ & 0.12 \\
Cholesterol & 0.98 & $0.80-1.17$ & 0.91 \\
2-h glucose at OGTT & 1.09 & $0.98-1.43$ & 0.41 \\
IGT intervention (Yes vs No) & 0.49 & $0.27-0.96$ & 0.031 \\
\hline
\end{tabular}

38 of 385 IGT men with complete data and without previous IHD died

Table 5. Independent risk factors for death from any cause in the cohort as a whole

\begin{tabular}{llll}
\hline & $\begin{array}{l}\text { Risk } \\
\text { ratio }\end{array}$ & $\begin{array}{l}\text { 95\% confi- } \\
\text { dence interval }\end{array}$ & $p$-value \\
\hline Body mass index & 1.02 & $0.99-1.05$ & 0.29 \\
Current smoking (Yes vs No) & 2.20 & $1.78-2.71$ & 0.0001 \\
Systolic BP & 1.01 & $1.01-1.02$ & 0.0001 \\
Cholesterol & 1.02 & $0.94-1.11$ & 0.62 \\
Forced vital capacity & 0.76 & $0.68-0.85$ & 0.0001 \\
Fasting glucose & 1.09 & $0.99-1.19$ & 0.08 \\
IGT (Yes vs No) & 1.19 & $0.84-1.70$ & 0.32 \\
Diabetes (Yes vs No) & 1.99 & $1.05-3.79$ & 0.04 \\
Treatment for hypertension & & & \\
(Yes vs No) & 1.08 & $0.72-1.62$ & 0.73 \\
\hline
\end{tabular}

427 died out of 5734 men in the cohort as a whole, with complete data and free of previous IHD

of IGT, and previous diabetes or medicated hypertension were available in 5734 subjects; 5256 of the NGT group, 256 of the IGT intervention group, 107 of the IGT routine treatment group, and 115 of the diabetes group (representing newly detected cases or patients with only dietary treatment). 427 died, 136 from IHD. With all variables in a regression model systolic $\mathrm{BP}$, forced vital capacity, diabetes and smoking predicted all-cause mortality (Table 5). In a stepwise procedure (data not shown) all-cause mortality was predicted by smoking $(p<0.0001)$, diabetes $(p<$ $0.0001)$, systolic BP $(p=0.0001)$, poor forced vital capacity $(p=0.0001)$, and fasting blood glucose $(p<0.05)$. IHD mortality was predicted by diabetes $(p<0.0001)$, systolic $\mathrm{BP}(p<0.0001)$, smoking $(p<$ $0.0001)$, cholesterol $(p<0.001)$, IGT $(p<0.01)$ and $\operatorname{BMI}(p<0.05)$.

Neither plasma insulin nor triglyceride values were an explanatory variable vis-à-vis subsequent IHD or all-cause mortality when tested in the models. As shown above, the actual level of systolic BP had an impact on both total and IHD mortality, whereas the information on whether medication or not (drug not specified) did not. The fitness related variables vital capacity and BMI were significant predictors of overall mortality and IHD mortality, respectively. In a subgroup from the whole cohort who underwent an ergometer test, estimated maximum oxygen uptake was $15 \%$ lower in men who died of IHD $(n=22)$ than in those who survived $(n=587)$ $\left[27.9 \pm 6.4\right.$ vs $32.8 \pm 8.7 \mathrm{ml} \cdot \mathrm{min}^{-1} \cdot \mathrm{kg}^{-1}($ mean $\pm \mathrm{SD})$, $p=0.002]$.

\section{Discussion}

Both IHD and all-cause mortality are increased not only in patients with diabetes $[3,19]$ but also in middle-aged non-diabetic subjects whose 2-h glucose values are in the upper range $[1,2]$. However, solely lowering blood glucose by pharmacological means seems to be insufficient to bring down the increased rate of IHD events. Only one of the three previous IGT intervention studies of reasonable length in which mortality was studied have shown any effect of pharmacological treatment or diet on mortality [2]. In the two British studies [1], this was hardly to be expected since treatment had no effect on NIDDM incidence. A common genetic antecedent hypothesis has even been proposed to explain the similarity in predisposition to IHD and diabetes [1]. However, in the Malmöhus county study, mortality reduction was not surprising because the 10-year NIDDM incidence in IGT subjects was reduced by diet regulation with and without pharmacological intervention [20].

In the present Malmö (city) NIDDM prevention study no excess 12 -year mortality was found in middle aged IGT men who started and for various periods $(90 \%$ for 6 years) participated in the feasibility study with diet and exercise [17]. Because of department routines no randomisation to the intervention programme could be performed. Basic advice (e.g. lifestyle and diet) was given to all IGT subjects, and intervention undertaken in the case of unregulated hypertension or increased liver enzymes. However, the difference in mortality between the two IGT groups could not be explained by group difference in the baseline risk factor profile except for a small difference in BP (for which correction was made in the regression analysis), or in the number who gave up smoking during the intervention programme. Few subjects were uninterested in participating in the intervention programme, and in most cases non-participation was attributable to department routines (e.g. change to written advice only during the end of the screening period or further check-ups of blood pressure), the case being taken over by the patient's own physician, changes of residence, or inability due to employment outside the region. Thus it is unlikely that the difference in mortality is a matter of self-selection to the intervention programme. Moreover, in the Malmöhus county study, that was performed in the nearby city of Lund $(20 \mathrm{~km})$, IGT was associated 
with an increased mortality both among those who received dietary treatment and in control subjects [2].

The close similarity of the survival curve of the IGT intervention group to that of the NGT group that was manifest at 6-year follow-up was still manifest at 12-year follow-up despite the higher NIDDM incidence in the interim. Over the 12-year study period as a whole there were no long-term serious adverse events of the intervention programme in terms of accidents or sudden deaths due to increased recreational physical activity, or of malignancies due to changes in diet. On the contrary mortality due to non-vascular causes was lower in the IGT intervention group than in the NGT group. Both IHD and all-cause mortality were approximately $50 \%$ lower in the IGT intervention group than in the IGT routine treatment group, as was the incidence of NIDDM [17]. In contrast, the IGT routine treatment group and the diabetes group both manifested the expected excess mortality.

The lack of difference in both IHD and all-cause mortality between the IGT intervention group and the background population (NGT) is remarkable in view of the multiple risk factors found in the IGT group, for example $14 \%$ (vs $4 \%$ ) treated for hypertension. BP was a strong predictor of IHD mortality both in the cohort as a whole and in the two IGT subgroups, findings consistent with those of other studies on mortality and cardiovascular disease associated with IGT $[1,20,21]$. This supports the idea of early intervention in high-risk groups, e.g. IGT and NIDDM [1, 22]. A 3-fold increase in 2-h plasma insulin was found in the IGT groups. Because insulin resistance is a crucial factor in glucose intolerance, instituting measures to improve insulin sensitivity would be the rational approach to reduce IHD mortality $[23,24]$. This is supported by the identification of certain risk groups for developing NIDDM (e.g. people with overweight, hypertension or family diabetes) in whom physical activity is associated with a dose-response effect on NIDDM incidence [9]. Our own previous short- and long-term studies have clearly shown multiple metabolic effects of diet and/or physical exercise in IGT subjects [17, 25, 26]. Diet and exercise act synergistically, yielding an improved glucose metabolism, increased insulin sensitivity, lowered blood pressure and a less atherogenic lipid profile (lowered triglyceride level and low: high density cholesterol ratio), improvements that reasonably explain the lowered mortality in the IGT intervention group [27].

The findings in this study that the 'sedentary trait' (obesity, low vital capacity and resting tachycardia) was associated with IGT and diabetes and that vital capacity was a predictor of overall mortality, and BMI and poor maximum oxygen uptake a predictor of IHD mortality are consistent with those of other studies. Such studies, which have mainly been carried out in non-diabetic cohorts, have shown a relationship to exist between poor cardiorespiratory fitness and both ischaemic heart disease (including primary cardiac arrest) and all-cause mortality [15]. The left ventricular mass is a strong predictor of mortality, and the cardioprotective effect of physical exercise may be due to the reduction in the left ventricular mass which occurs during training [28]. In one study fit men had lower age-adjusted all-cause death rates irrespective of glycaemic status [14], and in a prospective Finnish study, a strong graded correlation was found between physical fitness and myocardial infarction [12].

A possible explanation for the no-excess mortality is the successful long-term lifestyle modification programme combined with check-ups and re-inforcement based on test-result feed-back. Basic advice only (written or given orally) and routine treatment seem to be insufficient to induce lifestyle changes in sedentary and overweight individuals [17]. The Malmö study was conducted as a feasibility study to develop and test adherence to and health outcome of a long-term diet and exercise programme in this target group for NIDDM intervention. The purpose of the programme was to modify lifestyle in a manner readily acceptable to most patients at risk of NIDDM and the associated cardiovascular risk. However, it seems also to have had an effect on non-vascular mortality that was found to be lowest of all study groups. During the six years of active intervention with annual check-ups, the programme was found to be feasible with a very low drop-out rate $(10 \%)$, and for the first time ever it was shown that body weight could be kept down and physical fitness $\left(\mathrm{VO}_{2}\right.$ max $)$ improved in sedentary men with IGT between the ages of 48 and 54 years. This is in contrast to the difficulties of increasing physical activity by more general measures as was used in the Stanford five-city project [29]. The findings in the Malmö study of a reduced NIDDM incidence by diet and exercise has recently been confirmed in a large IGT study in northern China [30] although no mortality data have been reported.

The Malmö study shows that mortality is increased in middle-aged IGT men but that early intervention and lifestyle changes may be successful and result in lower than expected overall mortality over a 12-year period, due to reduction in both vascular and nonvascular deaths. Although the study was a non-randomised feasibility study, the results are compatible with the hypothesis that if NIDDM incidence could be reduced, the mortality rate in IGT will fall. In the Malmö study both these reductions were approximately $50 \%$, results that are compatible with those obtained in the Malmöhus county study. The new finding in the Malmö study is the beneficial effect of physical exercise on the long-term outcome of IGT which in turn derives support from observational studies showing relationship to exist between poor 
physical fitness and mortality. Because the effect on mortality was sustained for another 6 years after the active intervention programme, non-pharmacological treatment is to be recommended more often in high-risk groups for cardiovascular disease. Findings in the Malmö study support the view of increasing preventive efforts in IGT as outlined in a recent consensus conference [31].

\section{References}

1. Jarret J (1996) The cardiovascular risk associated with impaired glucose tolerance. Diabet Med 13: S15-S19

2. Knowler WC, Sartor G, Melander A, Scherstén B (1997) Glucose tolerance and mortality, including a substudy of tolbutamide treatment. Diabetologia 40: 680-686

3. Kuusisto J, Mykkänen L, Pyörälä K, Laakso M (1994) NIDDM and its metabolic control predict coronary heart disease in elderly subjects. Diabetes 43: 960-967

4. Knowler WC, Narayan KMV, Hanson RL et al. (1995) Preventing non-insulin-dependent diabetes. Diabetes 44: 483-488

5. Lindgärde F, Saltin B (1981) Daily physical activity, work capacity and glucose tolerance in lean and obese normoglycaemic middle-aged men. Diabetologia 20: 134-138

6. Eriksson K-F, Lindgärde F (1990) Impaired glucose tolerance in a middle-aged male urban population: a new approach for identifying high-risk cases. Diabetologia 33: 526-531

7. Eriksson K-F, Lindgärde F (1996) Poor physical fitness, and impaired early insulin response but late hyperinsulinaemia, as predictors of NIDDM in middle-aged Swedish men. Diabetologia 39: 573-579

8. Eriksson J, Franssila-Kallunki A, Ekstrand A et al. (1989) Early metabolic defects in persons at increased risk for non-insulin-dependent diabetes mellitus. N Engl J Med 321: 337-343

9. Helmrich SP, Ragland DR, Leung RW, Paffenbarger RS (1991) Physical activity and reduced occurrence of non-insulin-dependent diabetes mellitus. N Engl J Med 325: 147-152

10. Lakka TA, Venäläinen JM, Rauramaa R, Salonen R, Tuomilehto J, Salonen JT (1994) Relation of leisure-time physical activity and cardiorespiratory fitness to the risk of acute myocardial infarction in men. N Engl J Med 330: 1549-1554

11. Paffenbarger RS, Hyde RT, Wing AL, Hsieh C-C (1986) Physical activity, all-cause mortality, and longevity of college alumni. N Engl J Med 314: 605-613

12. Kohl HW, Gordon NF, Villegas JA, Blair SN (1992) Cardiorespiratory fitness, glycemic status, and mortality risk in men. Diabetes Care 15: 184-192

13. Sandvik L, Erikssen J, Thaulow E, Erikssen G, Mundal R, Rodahl K (1993) Physical fitness as a predictor of mortality among healthy, middle-aged Norwegian men. N Engl J Med 328: 533-537

14. Kaplan GA, Strawbridge WJ, Cohen RD, Hungerford LR (1996) Natural history of leisure-time physical activity and its correlates: associations with mortality from all causes and cardiovascular disease over 28 years. Am J Epidemiol 144: 793-797
15. Paffenbarger RS, Hyde RT, Wing AL, Lee-I-M, Jung DL, Kampert JB (1993) The association of changes in physical activity level and other lifestyle characteristics with mortality among men. N Engl J Med 328: 538-545

16. Tuomilehto J, Knowler WC, Zimmet P (1992) Primary prevention on non-insulin-dependent diabetes mellitus. Diab Metab Rev 8: 339-353

17. Eriksson K-F, Lindgärde F (1991) Prevention of type 2 (non-insulin-dependent) diabetes mellitus by diet and physical exercise. Diabetologia 34: 891-898

18. Sternby NH (1991) The role of autopsy in cancer registration in Sweden with particular reference to findings in Malmö. In: Riboli E, Delendi M (eds) Autopsy in epidemiology and medical research. IARC Scentific Publication 112, IARC Lyon pp 217-222

19. Panzram G (1987) Mortality and survival in type 2 (non-insulin-dependent) diabetes mellitus. Diabetologia 30: 123-131

20. Sartor G, Scherstén B, Carlström B, Melander A, Nordén Å, Persson G (1980) Ten-year follow-up of subjects with impaired glucose tolerance. Prevention of diabetes by tolbutamide and diet regulation. Diabetes 29: 41-49

21. Ohlson L-O, Bjurö T, Eriksson H, Svärdsudd K, Welin L, Wilhelmsen L (1989) A cross-sectional analysis of glucose tolerance and cardiovascular disease in 67-year-old men. Diabet Med 6: 112-120

22. Berglund G, Eriksson K-F, Israelsson B et al. (1996) Cardiovascular risk groups and mortality in an urban Swedish male population: the Malmö Preventive Project. J Int Med 239: 489-497

23. DeFronzo R, Ferrannini E (1991) Insulin resistance. A multifaceted syndrome responsible for NIDDM, obesity, hypertension, dyslipidemia, and atherosclerotic cardiovascular disease. Diabetes Care 14: 173-194

24. Bressler P, Bailey SR, Matsuda M, DeFronzo RA (1996) Insulin resistance and coronary artery disease. Diabetologia 39: $1345-1350$

25. Saltin B, Lindgärde F, Houston M, Hörlin R, Nygaard E, Gad P (1979) Physical training and glucose tolerance in middle-aged men with chemical diabetes. Diabetes 28 [Suppl 1]: 30-32

26. Lindgärde F, Eriksson K-F, Lithell H, Saltin B (1982) Coupling between dietary changes, reduced body weight, muscle fibre size and improved glucose tolerance in middleaged men with impaired glucose tolerance. Acta Med Scand 212: 99-106

27. Schneider SH, Morgado A (1995) Effects of fitness and physical training on carbohydrate metabolism and associated cardiovascular risk factors in patients with diabetes. Diabetes Rev 3: 378-407

28. Kokkinos PF, Narayan P, Colleran JA et al. (1995) Effects of regular exercise on blood pressure and left ventricular hypertrophy in African-American men with severe hypertenison. N Engl J Med 333: 1462-1467

29. Young DR, Haskell WL, Taylor CB, Fortman SP (1996) Effect of community health education on physical activity knowledge, attitudes, and behavior. The Stanford five-city project. Am J Epidemiol 144: 264-274

30. Pan X-R, Li G-W, Hu Y-H et al. (1997) Effects of diet and exercise in preventing NIDDM in people with impaired glucose tolerance. The Da Qing IGT and Diabetes study. Diabetes Care 20: 537-544

31. Genuth S (1996) Summary and prospectives on impaired glucose tolerance. Diabet Med 13: S29-S31 